\title{
Clinical Protocol Date Closed Standard Cancer Center Information Summary
}

National Cancer Institute

\section{Source}

National Cancer Institute. Clinical Protocol Date Closed Standard Cancer Center

Information Summary. NCI Thesaurus. Code C39358.

The Clinical Protocol Date Closed, Standard Cancer Center Information Summary for Cancer Center Support Grant Application, is the date when the clinical study was closed to accrual at the reporting Cancer Center during the 12-month reporting period. 